\title{
Chlorhexidine allergy
}

\author{
André Koch, UWe Wollina \\ Clinic for Dermatology und Allergology, Hospital Dresden-Friedrichstadt, Städtisches Klinikum Dresden
}

\section{Key words}

Disinfection anaphylaxis exanthema substantivity
Submitted

May 16, 2013

\section{Accepted}

July 1, 2013

German version www.springermedizin.de/ allergo-journal
Cite this as Koch A, Wollina U. Chlorhexidine allergy. Allergo J Int 2014; 23: 84-6

DOI 10.1007/s40629-014-0012-6

\section{Background}

Sensitivity to disinfectants plays a major role in the everyday lives of many people. Allergies, however, are far less common. Taking a detailed medical history and appropriate diagnostic allergy testing including skin test and if available in vitro tests are crucial in the professional workup of allergic responses to disinfectants. Here we present a case of a classic type-I reaction to chlorhexidine-containing disinfectants, that was confirmed by skin prick testing and specific IgE detection.

\section{Case report}

\section{Medical history}

The patient presented to his dentist in August 2012 due to a dental abscess. The dentist performed an incision, irrigated the wound, and applied a disinfectant gel (Chlorhexamed ${ }^{\circledR}$ gel $1 \%$ ). Within $10 \mathrm{~min}$ of completion of treatment, the patient experienced pruritus, abnormal numbness, and generalized exanthema. Articulation problems also appeared. The patient waited and his status largely normalized over the course of the subsequent $4 \mathrm{~h}$.

In October 2012, 2 months later, cystoscopy planned in the context of bladder-cancer follow-up and involving local application of mitomycin was performed by a urologist. As in the many examinations performed in preceding years, Instillagel ${ }^{\circledR}$ was used as the lubricating gel for urine catheter insertion. The symptoms described above reappeared within $30 \mathrm{~min}$, this time significantly more marked in character. The patient did not report circulatory dysregulation, shortness of breath, or gastrointestinal symptoms.

\section{General findings}

The patient, who was of normal weight and height, was in a relatively good general condition at the time of examination. Comorbidities included type2 diabetes, arterial hypertension, glaucoma, and bladder cancer.

\section{Skin findings}

No pathological skin findings were made at clinical examination.

\section{Laboratory findings}

Total immunoglobulin E (IgE) and specific $\operatorname{IgE}$ (sIgE) to chlorhexidine were determined as part of laboratory testing for allergies: chlorhexidine sIgE $1.29 \mathrm{kU} / \mathrm{l}$, CAP class 2 (normal value: $<0.35 \mathrm{kU} / \mathrm{l}$ ). Total IgE was normal at $95.7 \mathrm{U} / \mathrm{ml}$ (normal value: $<100 \mathrm{U} / \mathrm{ml}$ ). In order to exclude a latex allergy, specific IgE was also determined here, with no abnormal findings.

\section{Diagnostic Allergy Testing}

Epicutaneous testing: In a first step and to assess risk, patch testing with local anesthesia, parabens, chlorhexidine, and other components of medical products was performed to identify a trigger of the anaphylactic response. No pathological findings were observed either at $48 \mathrm{~h}$ or at $72 \mathrm{~h}$ following testing.

Skin prick testing: Skin prick testing with the suspected substances was then carried out as part of further testing, yielding a positive test reaction for chlorhexidine gluconate solution $0.5 \%$ after $20 \mathrm{~min}$ of observation in the form of wheal formation $(7 \mathrm{~mm})$ and mild erythema accompanied by local pruritus (Fig. 1). In comparison with negative and positive controls, this reaction could be classified as pathological.

$\begin{array}{ll}\text { Abbreviations } \\ \lg \mathrm{E} & \text { Immunoglobulin E } \\ \text { slgE } & \begin{array}{l}\text { Specific immunoglobulin E } \\ \text { MRSA }\end{array} \\ & \begin{array}{l}\text { Methicillin-resistant Staphylococcus } \\ \text { aureus strains }\end{array}\end{array}$




\section{Treatment and course}

Since the patient had already been on his way home on both occasions that the allergic responses had occurred, these responses had not been observed by a physician. Fortunately, the symptoms experienced by the patient were self-limiting and led to no severe immune response. At his next physician's visit, the patient reported the symptoms he had experienced, upon which the appropriate diagnostic steps were undertaken.

\section{Discussion and conclusion}

Chlorhexidine is a popular and widely used antiseptic agent, particularly in dentistry. It is most commonly used in the form of chlorhexidine digluconate. Due to its ability to bind to bacterial cell walls, where it causes precipitation of cytoplasmic proteins, chlorhexidine is an effective antiseptic. This effect is produced by damage to the bacterial permeability membrane. It has the advantage of being retained on the teeth and mucous membranes. Also relevant in this context is the agent's substantivity [1], meaning that it is almost $100 \%$ eliminated without absorption.

Outside the dental context, chlorhexidine is used for topical wound care, e.g., as a component in plasters as well as antiseptic creams and powders. It is also a tried and tested skin disinfectant. Among other things, it is also used in combination with mupirocin to eliminate resistant staphylococci (e.g., methicillin-resistant Staphylococcus aureus strains, MRSA) from the nasal vestibule [2].

Allergic reactions to chlorhexidine are relatively rare, particularly when one considers how widespread the use of the substance is in our living environment. Nevertheless, cases of contact allergies or even type-1 allergies are consistently reported in the literature $[3,4]$. A total of 50 cases were reported in a 2004 literature review [5]. The clinical relevance of a suspected allergy can be investigated by means of skin testing (patch, prick, and intracutaneous tests). In addition to these tests, it is also possible to determine specific IgE against chlorhexidine [6]. Although chlorhexidine allergy generally presents with mild dermal symptoms, it can also cause life-threatening anaphylaxis in the case of renewed exposure [3]. Allergic urticaria has also been reported [7]. Initial symptoms generally appear 20-40 min following allergen exposure, as confirmed by the present case. Since chlorhexidine is not a pharmaceutical product, and therefore not documented during surgical or diagnostic procedures, it is quite possible that it may be overlooked as a causative agent in the onset of an allergic reaction. As a result, the patient's risk of a possibly fatal outcome upon re-exposure in the future is increased. Given its excellent disinfecting and biochemical properties [1]

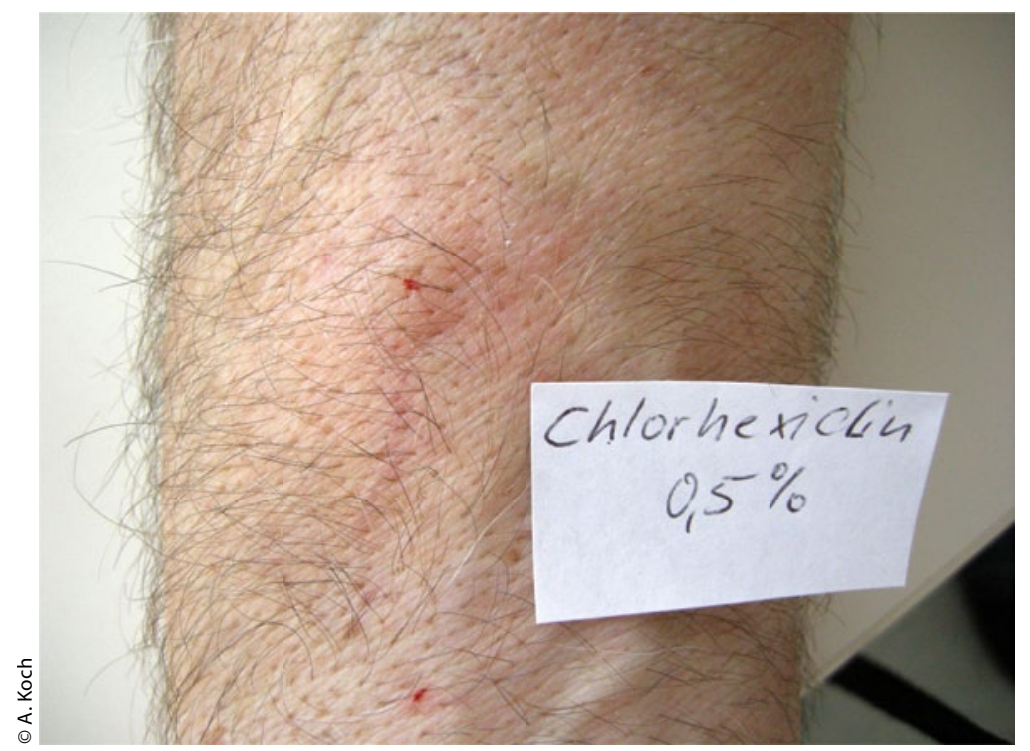

Fig. 1. Skin prick test using chlorhexidine gluconate $0.5 \%$

[2], the use of this substance is likely to continue increasing. Against this backdrop, the physician whose activities include allergology will undoubtedly encounter chlorhexidine allergies more frequently in the future.

\section{Dr. André Koch}

Klinik für Dermatologie und Allergologie

Krankenhaus Dresden-Friedrichstadt

Städtisches Klinikum

Friedrichstraße 41

01067 Dresden

E-Mail: koch-ae@khdf.de

\section{Conflict of interests}

The corresponding author states that there are no conflicts of interest.

\section{Cite this as}

Koch A, Wollina U. Chlorhexidine allergy. Allergo J Int 2014; 23: 84-6

DOI 10.1007/s40629-014-0012-6

\section{References}

1. Carrilho MR, Carvalho RM, Sousa EN, Nicolau J, Breschi L, Mazzoni A et al. Substantivity of chlorhexidine to human dentin. Dent Mater 2010; 26: 779-85

2. Bode LG, Kluytmans JA, Wertheim HF, Bogaers D, Vandenbroucke-Grauls $C M$. Preventing surgical-site infections in nasal carriers of Staphylococcus aureus. N Engl J Med 2010; 362: 9-17 
3. Friedlein $\mathrm{H}$, Rytter M, Simon JC. Anaphylaktische Reaktionen nach Kontakt mit Chlorhexidin-haltigen Gleitmitteln bei Blasenkathetereinlagen. Allergo J 2005; 4: 269-73

4. Krautheim AB, Jermann TH, Bircher AJ. Chlorhexidine anaphylaxis: case report and review of the literature. Contact Dermatitis 2004; 50: 113-6

5. Beaudouin E, Kanny G, Morisset M, Renaudin JM, Mertes M, Laxenaire MC et al. Immediate hypersensitivity to chlorhexidine: literature review. Eur Ann Allergy Clin Immunol. 2004 Apr; 36: 123-6

6. Nagendran V, Wicking J, Ekbote A, Onyekwe T, Garvey LH. IgE-mediated chlorhexidine allergy: a new occupational hazard? Occup Med (Lond) 2009; 59: 270-2

7. Chopra V, Chopra H, Sharma A. Allergic urticaria: a case report of rare skin allergy with a common mouthwash. Indian J Dermatol 2013; 58: 85 